\title{
Re-evaluation of multi-purpose reservoir yield
}

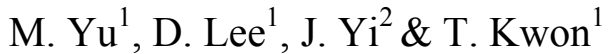 \\ ${ }^{1}$ Department of Civil and Transportation Engineering, \\ Ajou University, South Korea \\ ${ }^{2}$ Department of Civil Engineering, Ajou University, South Korea
}

\begin{abstract}
For a basin with existing reservoirs, the necessity of additional water demands as well as a re-evaluation of existing reservoir yield has been proposed. The objective of this study is to re-evaluate a multipurpose reservoir yield and to assess the possibility of additional water supply according to increase of downstream water demands. Andong and Imha reservoirs are selected for reevaluation. The standard reservoir operation rule model and the HEC-ResSim model were used for reservoir simulation for 30 years (1979-2008). In this study, water supply reliability was set up as $96.7 \%$ and $95.0 \%$ with yearly and monthly evaluation. In the case of $95.0 \%$ water supply reliability with yearly evaluation, water supply capability of Andong reservoir was evaluated as $893 \mathrm{MCM}$ and water supply capability of Imha reservoir was evaluated as $382 \mathrm{MCM}$, and that results showed that water yields for both reservoirs are less than the original designed yields.
\end{abstract}

Keywords: firm yield, reliability, water supply safety, water supply capacity.

\section{Introduction}

Water demand tends to continuously increase with population growth and industrial development; however, water supply does not. Many multi-purpose reservoirs for water supply have been constructed and have been in operation in Korea's major river since 1960 to resolve this problem. Yet, after the construction of these reservoirs, the water demands kept increasing due to the expansion of the country's agricultural needs and water pollution controls. Recently, the large new storage facilities developed to solve the increasing water demands have encountered challenges, such as difficulties in selecting a location, community backlash, and adverse environmental impacts, etc. Consequently 
attention has recently been focused on non-structural measures through the efficient operation of the existing reservoirs. To assess if non-structural methods in the existing reservoirs can meet the additional water demands, water yield, should be evaluated. While a water yield evaluation is performed when a reservoir is planned, the current reservoir operations reflect an environment that is changed since the reservoir was constructed. Furthermore, as time passes, changes occur in the downstream water demands and the basin environment and, therefore, it becomes necessary to re-evaluate water yield. In addition, a water yield evaluation is a very important procedure in establishing the plan and the operational measures for a reservoir and the water resource systems associated with them (Yi and Song [1]). However, since the water supply capabilities estimated by the various evaluation criteria differ, and no clear evaluation criteria exist, it is difficult to evaluate reservoir yield.

Until now, many methods have been proposed to determine reservoir capacity using a variety of hydrological data obtained during the reservoir's planning stage. Rippl [2] proposed methods to determine reservoir capacity using the mass volume curve; Alexander [3] proposed reservoir capacity decision techniques using the recurrence interval and gamma distribution of the annual amount; and Gould [4] generated synthetic inflow data based on stochastic analysis and analyzed its relationship to reservoir capacity. In addition, Hardison [5] generalized and proposed reservoir capacity estimation technique with the theoretical distribution of yearly inflow, and Teoh and McMahon [6] presented the relationship between reservoir capacity and reservoir yield in a regression equation using Gould's probability matrix procedure.

Wurbs and Bergman [7] presented the factors that affect the prediction of reservoir yield and reliability using the hydrologic elements of the basin, and Smithers and Walker [8] re-evaluated reservoir yield under a severe drought condition and presented the hydrological and sociological factors affecting the relationship between yield and reliability. Rittima and Vudhivanich [9] evaluated reservoir yield using resilience and reliability; Srivastava and Awchi [10] used linear programming and dynamic programming to optimize the hedging rule and evaluated reservoir yield; and Adeloye [11] proposed a generalized model of reservoir capacity, yield and reliability using multiple linear regression analysis and artificial neural network models.

This study established evaluation criteria for the water yield at Andong and Imha reservoirs on the Nagdong River in Korea. Water yields are also reevaluated using a reservoir simulation operation model.

\section{Water yield evaluation method}

Recently, establishing proper water yield evaluation criteria and estimating water yield using of a reservoir simulation model, has been widely used. Water budget analysis used to analyze the future water deficit of a basin estimates water deficit quantity of downstream basins through a reservoir operation where the water supply is constant during the simulation period. In contrast, water yield evaluation estimates potential maximum water supply, and the reliability of 
which is set through the reservoir simulation. This study evaluated water yield using a simulation model, although one of the limitations of this model is that it cannot find the optimum operation result, however, one of the strengths of this model is that it can express the system's status in detail.

\subsection{Water yield}

The water yield of a multi-purpose reservoir refers to the quantity of water that can be supplied from the reservoir, which is usually expressed by a yearly potential amount of water supply. The evaluation of a reservoir yield is an essential element in establishing a water resource supply plan including the security of new water resources and the determination of reservoir size. To evaluate the water yield of an existing reservoir that has been operating for several years, water deficit quantity and actual water yield are calculated by a reservoir simulation analysis, which calculates the water balance considering reservoir inflow, evaporation loss, rainfall, planned gate release during floods.

Since reservoir yield depends on the reservoir inflow, this yield changes each year and can be divided into a firm yield and a secondary yield. The firm yield can guarantee the water supply even during the maximum drought period. The secondary yield refers to the water supply quantity that exceeds the firm yield. The secondary yield can be used to determine the additional water yield.

\subsubsection{Water supply reliability}

Water supply reliability is an index that shows the degree to which the water supply can safely meet the expected water demand from a water supply facility, which is usually expressed by the frequency of occurrence of target drought flow duration or the average recurrence interval. Currently, no clear criteria have been established for determining water supply reliability; however, water supply reliability could be classified into firm yield criteria, which represents the reliability of the water supply even during periods of the maximum drought and reliability criteria, which includes the possibility of a water deficit for a certain period of time throughout the entire planning period [1].

The firm yield method is classified as a specific drought year method and multi-year drought periods method. A specific drought year method was primarily used until the 1970s to design the Andong, the Yongdam, and the Sueo reservoirs. The method ensures to satisfy all the water demands of the past maximum drought year without the possibility of the occurrence of a water deficit. The multi-year drought periods method was mainly used between 1970 and 1980 in Korea. It was used to design the Namgang, the Daecheong, and the Imha reservoirs. This method estimates the firm yield for all the reservoir's inflow conditions for approximately 20 years without the occurrence of a water deficit.

The reliability criteria have been used since the 1980s until now. These criteria are used to estimate the firm yield over a multi-year drought periods in which a water deficit occurs during a certain percentage of the entire period. The reliability criteria have been applied to the Choongju, the Bolyoung, and the Hwabuk reservoirs. 


\subsubsection{Evaluation criteria of water yield}

Water yield evaluation criteria can be broadly classified into water supply reliability and evaluation unit setting criteria. The water supply reliability criteria can be further differentiated into the firm yield method and the reliability method. Furthermore, in the reliability method, since the water supply is estimated differently based on the evaluation unit of the water deficit, it is necessary to establish evaluation unit criteria, even in cases with the same reliability.

In the reliability method, when the total analysis period is expressed as $p_{t}$ and the period of water deficit occurrence is expressed at $p_{f}$, the reliability $r(\%)$ is expressed in Eq. (1):

$$
r=\left(1-\frac{p_{f}}{p_{t}}\right) \times 100
$$

Because, the period of water deficit occurrence is the sum of the duration of the water deficient periods during the yearly, monthly, ten day, and daily evaluation units, the reliability value differs depending on the evaluation unit. Since water yield is estimated in terms of the supply volume when the water deficit condition occurs after the reliability value has been set in advance, it also becomes different depending on the evaluation unit. In other words, even if the water deficit period is same, if the evaluation unit is shorter, the estimated water yield becomes greater.

\subsection{Reservoir simulation model}

A reservoir simulation model considers an entire basin with one or more reservoirs as one system; this model considers the various input data that flows into the system and the various interactions that can occur in the basin and uses these data to examine the how the reservoirs operate. A standard operation rule and a HEC-ResSim model are used in this study.

\subsubsection{Model using standard operation rule}

In a reservoir simulated model, input data include inflow and rainfall, etc., while output data include release and losses. In general, rainfall in a reservoir and other losses are included in the inflow and the reservoir status change is simulated with water balance equations as seen in the Eqs. (2), (3), and (4), as follows:

$$
\begin{gathered}
S_{t}=S_{t-1}+I_{t}-O_{t}-E_{t} \\
S_{t, \text { min }} \leq S_{t} \leq S_{t, \max } \\
O_{t, \text { min }} \leq O_{t} \leq O_{t, \text { max }}
\end{gathered}
$$

where $S_{t}$ and $S_{t-1}$ represent the storage at times $t$ and $t-1$ respectively; $I_{t}, O_{t}$, and $E_{t}$, represent the inflow, release, and evaporation loss between times $t-$ 1and $t$ respectively; $S_{t, \min }$ and $S_{t, \max }$ represent the minimum and the maximum storage at time $t$, respectively; and $O_{t, \min }$ and $O_{t, \max }$, represent the minimum and the maximum release at timet, respectively. 
Reservoir simulation technique can clearly present changes in the reservoir's storage status. This technique can be used with complex operation policies that can occur in a real operational situation.

This study considered a standard operation policy (SOP) widely applied to general reservoir operation problems. In SOP, if sufficient water resource is available only the target water is supplied, whereas if the expected water resource is insufficient, the water supply is decreased. The SOR is expressed in Eqs. (5-7), and presented in Fig. 1.

$$
\begin{gathered}
O_{t}=S_{e f f, t-1}+I_{t} \quad \text { if } S_{e f f, t-1}+I_{t} \leq D_{t} \\
O_{t}=D_{t} \quad \text { if } D_{t} \leq S_{e f f, t-1}+I_{t} \leq S_{\text {max }_{e f f, t}} \\
O_{t}=S_{e f f, t-1}+I_{t} \text { if } S_{e f f, t-1}+I_{t}-D_{t}>S_{\text {max }_{e f f, t}}
\end{gathered}
$$

where $O_{t}$ refers to the reservoir supply (water intake and release) at time $t ; S_{e f f, t}$ and $S_{\text {eff } t-1}$ refer to the reservoir storage (effective storage) between time $t$ and $t-1 ; I_{t}$ refers to the reservoir inflow at timet; $D_{t}$ refers to the water demand at timet; and $S_{\max _{\text {eff }, t}}$ refers to the maximum reservoir storage at time $t$.

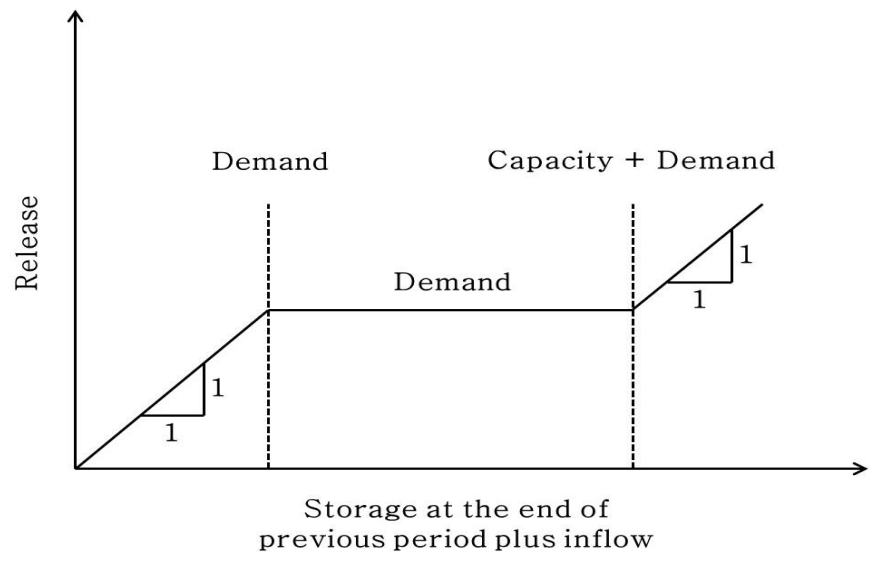

Figure 1: Standard operation rule S-shaped curve (Shih and Revelle [12]).

\subsubsection{HEC-ResSim}

HEC-ResSim is a next-generation reservoir simulation model that replaces HEC5 developed by the US Army Corps of Engineers for more than 20 years. With the current version 3.0, reservoir specifications, initial values, the inflow situations, and various constraints can be considered.

(1) Operate the flood control storage and the conservation storage of each reservoir in a basin.

(2) Estimate a reservoir flood control plan and the potential water supply.

(3) Estimate the hydropower energy generation.

(4) Estimate flood damage costs, flood control costs, and the hydropower benefits. 
(5) Estimate the impact of the reservoirs system on a basin based on the temporal and spatial distribution of outflow.

In addition, the reservoir operation and management and the correction of data can easily be performed through GUI, and the objective functions and constraints can be applied through the model. It is also possible to consider conditions, such as if-then-else, into this reservoir simulation model directly.

\section{Evaluation criteria and reservoir yield}

\subsection{Study area}

The suggested methodologies are applied to the Andong and the Imha reservoirs, located in the upper Nagdong River basin, to determine water yield and to evaluate the recent new demands. The Nagdong River basin is located in southeastern part of South Korea (longitude: $127^{\circ} 29^{\prime}-129^{\circ} 18^{\prime}$, latitude: $35^{\circ} 03^{\prime}$ $\left.37^{\circ} 13^{\prime}\right)$. The river basin area is about $23,700 \mathrm{~km}^{2}$, and the length of the river is $521.5 \mathrm{~km}$. Fig. 2 shows the basin map of the Nagdong River.

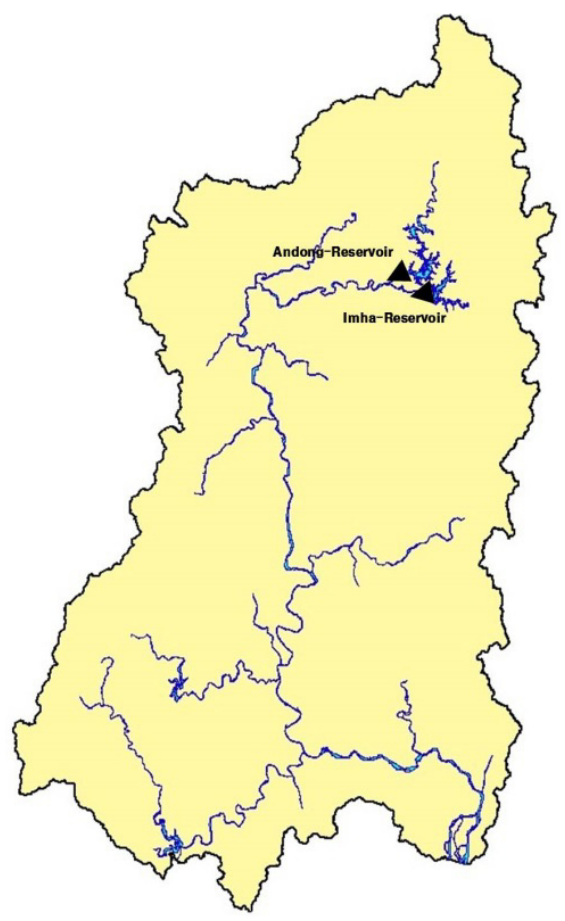

Figure 2: $\quad$ Nakdong River Basin.

Andong reservoir was built in 1977 as part of the river basin's comprehensive development project to provide irrigation and domestic water in addition to 
control flood. The total reservoir capacity of Andong reservoir is 1,248MCMand the effective reservoir capacity is 1,000MCM. In the Nakdong River Basin master plan, the annual planned water supply for Andong reservoir is $926 \mathrm{MCM}$, and the domestic and industrial water supply was planned as $450 \mathrm{MCM}$. The irrigation water was planned as $300 \mathrm{MCM}$, and the instream flow was planned as $176 \mathrm{MCM}$.

Imha reservoir was built in 1993 as part of the Nakdong River Basin comprehensive development project. It was designed to supply domestic, industrial and irrigation water to the basin as well as to control flood and generate hydro energy. The total reservoir capacity of Imha reservoir is 595MCM and the effective reservoir capacity is 424MCM. The domestic and industrial water supply was planned as $269 \mathrm{MCM}$, and the irrigation water supply was planned as 13 MCM. The instream flow was planned as $215 \mathrm{MCM}$. When the Imha reservoir was designed, the annual water supply was estimated as 497MCM.

\subsection{Water yield evaluation criteria}

Water supply reliability considered in this study is $96.7 \%$, and $95.0 \%$. The annual, monthly, and daily units are considered. The water yield for the annual basis evaluation unit with $96.7 \%$ reliability refers to potential water supply during one year water deficit occurrence over a 30 year period. The water yield for the monthly basis evaluation unit with a reliability of $96.7 \%$ refers to the potential water supply during 12 months water deficit occurrence over a 360 month period. The water yield for the yearly basis evaluation with $95.0 \%$ reliability refers to the potential water supply during a 1.5 year water deficit occurrence over a 30 year period. The water yield for the monthly basis evaluation unit with $95.0 \%$ reliability refers to the potential water supply during an 18 month water deficit occurrence over a 360 month period.

\section{Re-evaluation of reservoir yield}

\subsection{Inflow data and operation policies}

For the Andong and Imha reservoirs, the reservoir simulation was performed by using daily inflow data for 30 years, from 1979 until 2008. Since Andong reservoir was completed in 1977, there are inflow data since 1977. However, Imha reservoir was completed in 1993 and no inflow data exist for the period from 1979 until 1992. Therefore, the daily stream flow data from 1979 until 1992 were converted during the simulation period. Imha reservoir diverted $3.0 \mathrm{~m}^{3} / \mathrm{s}$ in order to improve water quality of Gumho River from 2001 and also diverted $1.8 \mathrm{~m}^{3} / \mathrm{s}$ to supply industrial water the Pohang area.

This study defined the water yield deficit period as the period in which the reservoir's water level dropped to the low-water level, so it cannot supply as much as in the original plan. 


\subsection{Water yield by water supply reliability}

Applying the SOR model to the annual basis evaluation of the Andong reservoir, with a reliability of $96.7 \%$, the annual potential water yield was $861 \mathrm{MCM}$. Using the HEC-ResSim model, that value was 835MCM. Applying the SOR model to the monthly basis evaluation with a reliability of $96.7 \%$, the annual potential water yield was 942MCM. With the HEC-ResSim model, that value was 925MCM. Applying the SOR model to the annual basis evaluation with a reliability of $95.0 \%$, the annual potential water yield was $893 \mathrm{MCM}$. Using the HEC-ResSim model, that value was be $847 \mathrm{MCM}$. Applying the SOR model to the monthly basis evaluation with a reliability of $95.0 \%$, the annual potential water yield was 965MCM. Using the HEC-ResSim model, that value was 959MCM.

Applying the SOR model to the annual basis evaluation of the Imha reservoir, with a reliability of $96.7 \%$, the annual potential water yield was 362MCM. Using the HEC-ResSim model, that value was 356MCM. Applying the SOR model to the monthly basis evaluation with a reliability of $96.7 \%$, the annual potential discharge was 419MCM. Using the HEC-ResSim model, that value was 417MCM. Applying the SOR model to the annual basis evaluation with a reliability of $95.0 \%$, the annual potential water yield was 382MCM.Using the HEC-ResSim model, that value was 359MCM. Applying the SOR model to the monthly basis evaluation with a reliability of $95.0 \%$, the annual potential water yield was 462MCM. Using the HEC-ResSim model, that value was 451MCM. The estimated water yields for Andong and Imha reservoirs are shown in Table 1 .

Table 1: $\quad$ Water supply capacity for reliabilities and evaluating units.

\begin{tabular}{|c|c|c|c|c|c|c|c|}
\hline & \multirow{2}{*}{\multicolumn{2}{|c|}{ Section }} & \multirow{2}{*}{$\begin{array}{l}\text { Base } \\
\text { Yield }\end{array}$} & \multicolumn{2}{|c|}{$\begin{array}{c}\text { Reliability } \\
96.7 \%\end{array}$} & \multicolumn{2}{|c|}{$\begin{array}{c}\text { Reliability } \\
95.0 \%\end{array}$} \\
\hline & & & & SOR & HEC-ResSim & SOR & HEC-ResSim \\
\hline \multirow{6}{*}{$\begin{array}{c}\text { Water } \\
\text { Supply } \\
\text { Capacity } \\
\text { (MCM/ } \\
\text { year) }\end{array}$} & \multirow{2}{*}{$\begin{array}{c}\text { Andong } \\
\text { reservoir } \\
(1979- \\
2008)\end{array}$} & $\begin{array}{c}\text { Annual } \\
\text { Unit }\end{array}$ & \multirow{2}{*}{926} & 861 & 835 & 893 & 847 \\
\hline & & $\begin{array}{c}\text { Monthly } \\
\text { Unit }\end{array}$ & & 942 & 925 & 965 & 959 \\
\hline & \multirow{2}{*}{$\begin{array}{c}\text { Imha } \\
\text { reservoir } \\
(1979- \\
2008)\end{array}$} & $\begin{array}{c}\text { Annual } \\
\text { Unit }\end{array}$ & \multirow{2}{*}{497} & 362 & 356 & 382 & 359 \\
\hline & & $\begin{array}{l}\text { Monthly } \\
\text { Unit }\end{array}$ & & 419 & 417 & 462 & 451 \\
\hline & \multirow{2}{*}{$\begin{array}{c}\text { Total } \\
(1979- \\
2008)\end{array}$} & $\begin{array}{c}\text { Annual } \\
\text { Unit }\end{array}$ & \multirow{2}{*}{1,423} & 1,223 & 1,191 & 1,276 & 1,206 \\
\hline & & $\begin{array}{c}\text { Monthly } \\
\text { Unit }\end{array}$ & & 1,361 & 1,342 & 1,427 & 1,410 \\
\hline
\end{tabular}

\section{Conclusion}

Water supply reliability is established as the annual and monthly basis with a reliability of $96.7 \%$ and $95.0 \%$, respectively in order to study the possibility of additional water yields from Andong and Imha reservoirs. A reservoir simulation 
was performed using inflow data obtained for a 30years period from 1997 until 2008 to re-evaluate the water yield from both reservoirs. For Andong reservoir, the annual yield with a reliability of $95.0 \%$, which was used by the Ministry of Construction and Transportation of Korea when the reservoir was designed. The yearly reservoir yield was estimated to be $893 \mathrm{MCM}$ by the SOR model and 847 MCM by HED-ResSim model.Those values are lower than 926 MCMnoted in the master plan. Therefore, it is difficult to supply an additional water yield. Using the SOR model, the annual water yield from Imha reservoir was 382MCM. With HEC-ResSim model, the annual water yield for this reservoir was 359MCM. Both of those values are lower than the water supply value of 497MCM indicated in the master plan, so it is also difficult to increase the water yield from these reservoirs.

Finally, when using water supply reliability as one of the criteria for the evaluation of a reservoir yield, the drought conditions and the future water demand of the basin should be considered. Furthermore, water supply reliability should be established as an appropriate and integrated policy with regard to politics, society, and economy. In addition, just as the existing reservoir flood control capability is increased to prepare for abnormal flood due to climate change, the reservoir water yield criteria should be re-evaluated in order to prepare for severe droughts.

\section{Acknowledgement}

This study was financially supported by the Construction Technology Innovation Program (08-Tech-Inovation-F01) through the Research Center of Flood Defence Technology for Next Generation in Korea Institute of Construction and Transportation Technology Evaluation and Planning (KICTEP) of Ministry of Land, Transport and Maritime Affairs (MLTM).

\section{References}

[1] Yi, J.E., and Song J.W., Evaluation of Water Supply Capacity for MultiPurpose Dam Using Optimization and Simulation Techniques. Journal of the Korean Society of Civil Engineers, Vol. 22, No.6B, pp. 811-818, 2002.

[2] Rippl, W., Capacity of storage reservoirs for water supply. Minutes of Proceedings Institution of Civil Engineers, 71, pp. 270-278, 1883.

[3] Alexander, G.N., The use of the Gamma distribution in estimating regulated output from storages. Civil Engineering Transactions, The Institution of Engineers, Australia, CE4 (1), pp. 29-34, 1962.

[4] Gould, B.W., Statistical methods for estimating the design capacity of dams. Journal of the Institution of Engineers, Australia, 33(12), pp. 405416, 1964.

[5] Hardison, C.H., Storage to augment low flows. Proceedings of Reservoir Yield Symposium. Water Research Association, Oxford, UK., Part I , p. 8, 1965. 
[6] Teoh, C.G. and McMahon, T.A., Evaluation of rapid reservoir storage-yield procedures. Advances in Water Resources, 5, pp. 208-215, 1982.

[7] Wurbs, R.A., and Bergman, C.E., Evaluation of factors affecting reservoir yield estimates. Journal of Hydrology, Elsevier BV, Vol. 112, Issue 3-4, pp. 219-235, 1990.

[8] Smithers, H., and Walker, S., Reassessment of water resources in northwest England as a result of the 1995-1996 drought. Sustainability of Water Resources under Increasing Uncertainty, IAHS-AISH Publication, no. 240, pp. 173-181, 1997.

[9] Rittima, A., and Vudhivanich, V., Storage-Yield-Resilience-Reliability Relationship of Mun Bon Reservoir. Proceedings of 41st Kasetsart University Annual Conference, Bangkok, Thailand, pp. 55-64, 2003.

[10] Srivastava D.K., and Awchi T.A., Storage-Yield Evaluation and Operation of Mula Reservoir, India. Journal of Water Resources Planning and Management, ASCE, Vol. 135. No. 6. pp. 414-425, 2009.

[11] Alexander, G.N., The use of the Gamma distribution in estimating regulated output from storages. Civil Engineering Transactions, The Institution of Engineers, Australia, CE4 (1): 29-34, 1962.

[12] Shih, J. S., and Revelle, C. S., Water supply operation during drought: continuous hedging rule. Journal of Water Resources Planning and Management, Vol. 120, No. 5, pp. 613-629, 1994. 